\title{
The implant-abutment connection and its impact on prevention of peri-implant diseases and crestal bone stability-an academic and clinical evaluation of the literature
}

\author{
Georgios E. Romanos ${ }^{1,2}$ \\ ${ }^{1}$ Department of Periodontology, Stony Brook University, Stony Brook, New York, USA; ${ }^{2}$ Department of Oral Surgery and Implant Dentistry, School \\ of Dentistry, Johann Wolfgang Goethe University, Frankfurt, Germany \\ Correspondence to: Georgios E. Romanos, DDS, PhD, Prof Dr med dent. Department of Periodontology, Stony Brook University, Stony Brook, New \\ York, USA. Email: georgios.romanos@stonybrookmedicine.edu.
}

\begin{abstract}
The crestal bone stability and the long-term presence of bone crest at the level of the implant platform to achieve implant success and esthetic outcomes is of paramount importance. The paper presents and academic and clinical evaluation of the literature on the characteristic features of the implantabutment connection, the main characteristic of an implant collar and platform to control the microgap and bacteria proliferation leading to prevention of crestal bone loss. In addition, the role of the abutmentdisconnection, the size of the horizontal mismatch, and last but not least the importance of the Morsetapered connection has been discussed as fundamental requirements for improvement of implant success and long-term successful esthetic outcomes. The author presents also clinical and histological information on the implant abutment connection, which is beneficial for the bone stability. All this scientific information must be critically analyzed in the modern implant dentistry when new implant surfaces and implant-abutment connections are developed to improve strategies for better osseointegration and sustainable crestal bone stability.
\end{abstract}

Keywords: Crestal bone loss; platform switching; prevention

Received: 07 June 2021; Accepted: 26 September 2021; Published online: 22 October 2021.

doi: $10.21037 /$ fomm-21-73

View this article at: https://dx.doi.org/10.21037/fomm-21-73

The crestal bone stability and the long-term presence of bone crest at the level of the implant platform to achieve implant success and esthetic outcomes is of paramount importance. Therefore, clinicians and manufacturers have tried over the years to develop a variety of implant collar designs with the presence of threads and micro-threads (1), absence of a microgap, implant-abutment connections allowing lack of micromovements and a better sealing against bacteria $(2,3)$, as well as a development of one-piece (tissue level) implants (4).

\section{Implant collar characteristics}

Different studies showed that micro-threads might be an avenue for crestal bone stability (5-7), but there is no confirming information about this design feature as a requirement for all implant designs. Although even a recent systematic review showed less crestal bone loss with dental implants that had a micro-threaded neck design than with machined-surface or conventional rough-surface dental implants (8), most implant manufacturers today develop implant designs without micro threads and present radiologically excellent crestal bone levels.

However, this marginal bone stability is required when patients have compromised bone qualities and systemic conditions (9).

\section{The implant-abutment joint and how to minimize the gap}

Early studies evaluated the implant-abutment interface and 


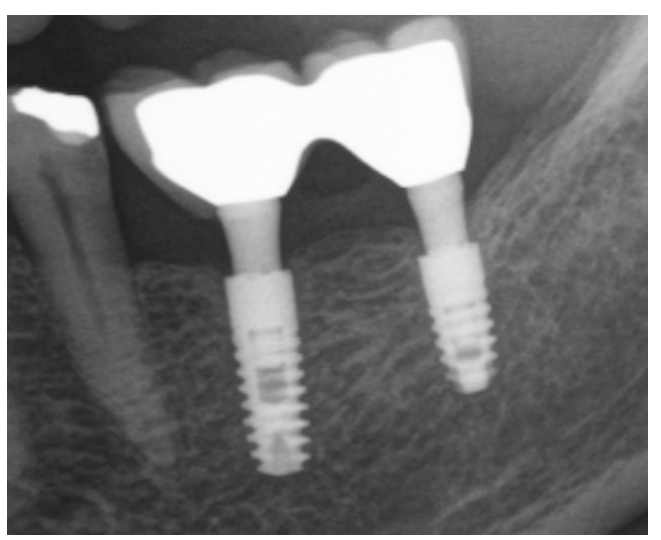

Figure 1 Subcrestal and epicrestal implant placement in the same patient after 3-month healing and one-abutment concept. This radiograph presents the crestal bone stability 25 years after loading.

its impact on implant stability. Binon (10) showed a direct correlation between the implant-abutment joint misfit and screw joint loosening. A rotational misfit of under 2 degrees provided the most stable and predictable screw joint. Therefore, there is a need to eliminate this misfit in rotations during the function to avoid screw-loosening leading to abutment loosening (11).

Previous studies from the University of Gothenburg demonstrated the association between peri-implant soft tissue inflammatory reaction and microgap in butt-joint implant-abutment connections (12). The impact of the microgap on the crestal bone level was firstly investigated by Hermann et al. (13), in canines. The studies showed that significant crestal bone loss occurs in two-piece implant designs even with the smallest-sized microgaps (<10 microns) combined with possible movements between implant components. In addition, further studies demonstrate that the rough/smooth implant interface, as well as the location of the microgap, have a significant effect on marginal bone formation. Bone remodeling occurs rapidly during the early healing phase after implant placement for non-submerged implants and after abutment connection for submerged implants (14).

However, studies by Weng et al. $(15,16)$ with unloaded implants in dogs showed that different microgap designs cause different shapes and sizes of the peri-implant ('dishshaped') bone defects in submerged placed implants both in equicrestal and subcrestal positions (16). Subcrestal positioning of an external butt-joint microgap may lead to faster radiographic bone loss before implant loading (16).
Recent studies by Sasada and Cochran (17) showed that implants without micro-threads and absence of a microgap (one-piece implants) have the best prognosis in the long term. However, it is difficult to place one-piece (tissue level) implants in specific clinical conditions. For instance, when angulations are needed, clinicians are challenged to place implants parallel to each other. In addition, in case of crestal bone loss in the esthetic zone, visualization of the implant neck might compromise esthetics, and therefore all these limitations reduce the selection of one-piece implant designs in daily practice. Two-piece implants were developed to find solutions to clinical problems with the aim of reducing or eliminate the issues of the microgap. First implant designs having reduced diameter of abutment neck compared to the diameter of the implant were developed in the 80s. In 1985, Thomas Driskell introduced the first unique sloping shoulder concept designed to help maintain crestal bone height and interdental papillae with the name "Bicon ${ }^{\circledR}$ " implant system (18). Almost the same time Nentwig and Moser (19) illustrated the design of a concept with reduced diameter abutment neck, and a progressive thread design for better stability and apical load transfer, which was introduced in the German market $\left(\mathrm{NM}^{\circledR}\right.$-implant system, Krupp Co.) and was modified slightly later (Ankylos ${ }^{\circledR}$ implant system Dentsply Co.). Due to the difference in the load transfer towards the apical part of the implant (20), this implant design showed promising clinical outcomes in the conjunction between teeth and implants using cementretained fixed restorations (21).

The absence of a microgap is also possible in systems with a tight and rigid interface between implant and abutment, which creates a "virtually" one-piece implant due to lack of micromovements and bacterial accumulation (bacterial seal). In general, the type of mechanical connection is associated with micromovements under loading conditions. Conical (Morse-cone) connections present stability under loading $(22,23)$ and are beneficial in clinical settings. Recent systematic reviews, comparing conical versus non-conical implant-abutment connection systems in their in vitro and in vivo performances, demonstrated that the Morseconnection provides a better abutment fit, stability, and seal performance (24). Therefore, more implant systems today move towards these developments and improvements.

A retrospective clinical study showed crestal bone stability around implants with Morse-tapered (conical) connections when these implants have been loaded after healing without abutment disconnection (Figure 1).

In addition, the design features of the implant-abutment 


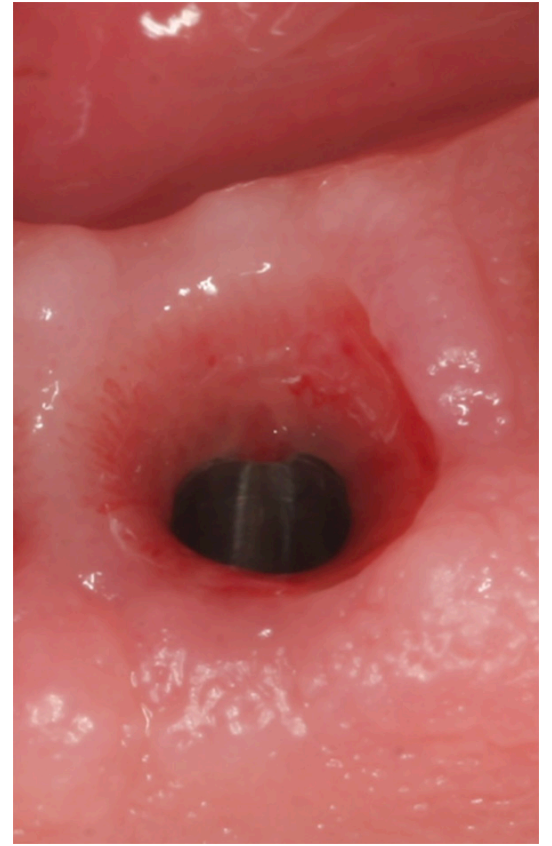

Figure 2 Soft tissue stability 12 years after implant loading on an implant with Morse tapered connection and platform switching.

connection allow soft-tissue stability (Figure 2) and papilla formation due to the presence of supported bone crest (Figure 3).

The data of this study present long-term crestal bone stability (13 years post-op) for subcrestally and epicrestally placed implants (25) with PS. Also, studies from another scientific group confirm this concept using the same implant design. The marginal bone level changes around platform-switched implants with the same geometry were not affected by the epicrestal or subcrestal location of the implant platform (26) within an 18-month loading period. Additional studies evaluating implants placed in different apico-coronal positions (at the bone level or $2 \mathrm{~mm}$ subcrestally) showed similar clinical outcomes three years after prosthetic loading in both groups of implants, but less peri-implant marginal bone loss group of subcrestal placed implants (27).

\section{The role of abutment-disconnection}

Furthermore, there is evidence that implants, which have been connected and disconnected with the healing abutments present an apical migration of the peri-implant long junctional epithelium and crestal bone loss (28). The

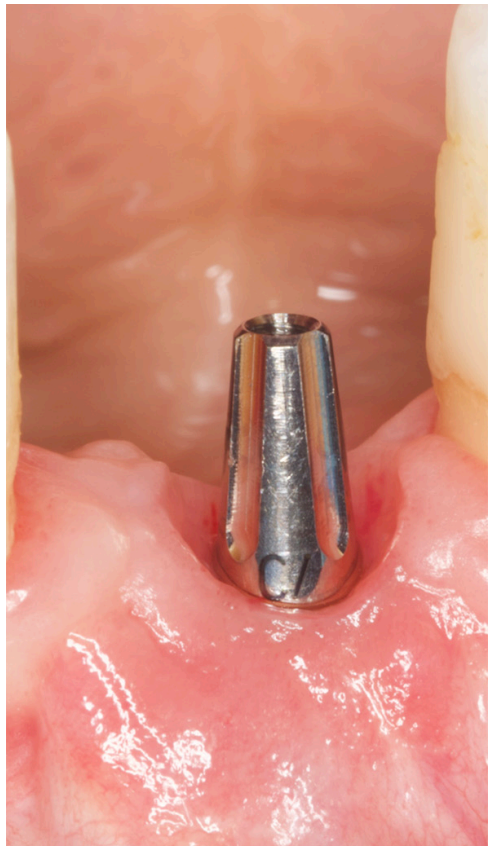

Figure 3 Peri-implant soft tissue stability 6 years after implant loading demonstrating the papilla formation due to platform switching and Morse-tapered implant-abutment connection.

findings from these studies performed in beagle dogs indicate that the dis- and subsequent reconnections of the abutment $(5 x)$ compromised the mucosal barrier and resulted in a more "apically" positioned zone of connective tissue in the peri-implant tissues. Thus, the additional marginal bone resorption observed due to abutment manipulation may result from marginal tissue reactions to establish the proper "biological width" of the mucosalimplant barrier.

Even studies by Abrahamsson et al. (29) showed a similar composition around dental implants with different implant designs (i.e., Astra, Nobel and Straumann), the examined implants with conical implant-abutment connections and PS (Astra system) presented a shorter long junctional epithelium. In addition, when plaque-induced inflammation was initiated after placement of ligatures around implants with different types of implant-abutment connections, the level of peri-implant soft tissue infiltrate was evaluated and showed a statistically significant difference in the inflammatory reaction, with less inflammation around implants with PS (Astra design). However, the authors concluded that the marginal bone levels, measured from the abutment/fixture border, did not differ between the three systems (30). 


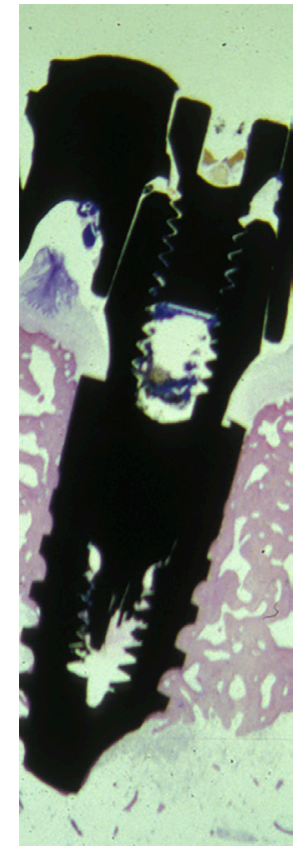

Figure 4 Marginal crestal bone stability around implant with Morse-tapered connection and platform switching (monkey). There is lack of space at the implant-abutment interface under loading conditions in the histological specimen to be observed, which proves the sealing at the implant-abutment interface.

Also, repeated $(2 \times)$ dis-/re-connection at four and six weeks (test) around titanium and zirconia implants in dogs with a horizontal mismatch of $0.4 \mathrm{~mm}$ presented dimensional changes of peri-implant soft and hard tissues (31).

The one-abutment concept, which was proven in monkeys showed lack of micromovements under loading conditions and a seal in the implant-abutment interface when conical implant-abutment connections were used (Figure 4). The clinical impact of the Morse-tapered connections was also confirmed clinically by other investigators, showing a longitudinal stable soft tissue dimension (32).

Advanced surgical protocols with immediate loading of dental implants placed in healed ridges and implants placed in fresh extraction sockets and restored with the final abutments without removal were documented and showed excellent success after many years of function $(33,34)$.

Degidi et al. (35) confirmed the concept of one-abutment in a clinical study with a 2 -year follow-up period. The authors showed that non-removal of abutments placed at the time of surgery improves the stability of healed soft and hard tissues around the immediately restored, subcrestally placed tapered single maxillary implants in fresh extraction sockets. In addition, mandibular immediately loaded implants in partially edentulous patients successfully used the one-abutment concept (36).

Further animal and clinical studies with immediately loaded implants using the same abutment from the time of implant placement (without disconnection) concluded to similar clinical outcomes (37). Specifically, the prosthetic restoration was fabricated after the impression of the abutment without disconnection, and the prosthesis was cement-retained (38-40). In addition, it was shown in heavy smokers, no significant difference in the clinical outcomes when implants are loaded immediately $(41,42)$. Human histological autopsy report from a heavy smoker presented an excellent osseointegration with soft and hard tissue stability around immediately loaded implants (43).

In all these studies, implants with a narrow abutment neck diameter than the implant diameter (platform shifting) were used following a concept of abutment placement and without removal. The strategies and treatment approach to accomplish soft and hard tissue stability were recently published (44).

\section{Size of the horizontal mismatch}

The reduced diameter of the abutment neck compared to the implant diameter, so-called "platform switching" (PS) was introduced in the international literature by Gardner (45) and later by Lazzara and Porter (46) confirming the maintenance of the crestal bone level for platform-switched implants based on human histological evaluation (47).

Quantitative analysis based on seven systematic reviews with meta-analysis indicated positive peri-implant bone preservation for implants restored with an implantabutment mismatching (48). This study suggested that marginal bone level alterations could be related to the extent of implant/abutment mismatching. Furthermore, marginal bone levels were better maintained at implants restored according to the PS concept.

In a previous evaluation of the literature on PS, seven studies reported that implants placed according to this concept did not minimize crestal bone loss compared with non-platform switched (NPS)-implants. Three-dimensional (3D) implant positioning, the width of alveolar ridge, and control of micromotion at the implant-abutment interface are the more critical factors that influence crestal bone levels than PS (49). In addition, canine studies with PSand NPS-implants showed that the bone remodeling was 
minimal in both groups and that the PS may not be of crucial importance for the maintenance of the crestal bone level (50).

However, in a relatively new investigation, the crestal bone resorption was also evaluated around implants with platform-matched and platform switched interfaces. Implants with platform-matched abutment groups demonstrated a higher amount of metal ion release and more surface damage. In contrast to these findings, the PS concept reduces the tribo-corrosion products released from dental implants, which may minimize the adverse tissue reactions leading to peri-implant bone loss (51). These findings highlight the positive effect of PS due to reduced osteoblast viability and secretion of cytokines (52) controlling further corrosive phenomena at the implantabutment interface.

The horizontal mismatch between the abutment neck and implant platform was evaluated in a dog study (53). It showed that a mismatch of $0.85 \mathrm{~mm}$ between the implant and abutment yielded more coronal levels of bone-toimplant contact and a reduced height of the peri-implant soft tissue (biologic width), especially at the buccal aspect, if the implant shoulder was placed at the bone level.

However, the design of the transmucosal component can influence the establishment of the peri-implant biologic width on implants with PS. Specifically, flat, and wide emergence profiles $\left(45^{\circ}\right.$ angulation with implant long axis compared to narrow emergence profiles with $15^{\circ}$ angulation with implant long axis) induced an apical displacement of the peri-implant biologic width and more crestal bone loss (54).

Studies also in canines showed that independent of the shape of the horizontal mismatch (concave or no, mimicking the currently marketed bone-level implant from Straumann implant design), implants with concave abutment neck present thick, soft tissue around the neck and, therefore thicker transmucosal component as a protective barrier against bacteria. However, a crestal bone loss was observed except if the implants are fabricated as one-piece implants with concave transmucosal portion. The study promoted the concept of one-piece dental implants (55).

Further studies by Cochran et al. (56) confirmed that the bone loss around implants with non-matching implantabutment diameters was significantly less (five- to six-fold) than that reported for bone-level implants with matching implant-abutment diameters (butt-joint connections).

Without doubt the studies in canines are fundamental but clinical evidence is required in the future using this type of designs.

\section{The morse-tapered connection}

There are many implants in practice today using conical implant-abutment interfaces, but the degree of angulation impacts mechanically the anti-rotational stability. In engineering the taper angle of the Morse taper varies somewhat with size but is typically 1.49 degrees. Specifically, from the mechanical engineering perspective, the clamping force in conical connections originates a large frictional resistance. In addition, the manufacturer has included a non-rotational interconnection (like a hex) to add rotational stability for an accurate placement of the prosthetic abutment/restoration.

It was also shown that the 11-degree Morse taper demonstrated better resistance to microbial leakage than the butt-joint connection (57). A misfit of the implant-abutment interface leads to abutment overload, screw loosening, incorrect force transmission to the implant body and the peri-implant crest of bone and bacterial proliferation, and potential risks for implant fracture.

It must be considered that a complete fit of the abutment with the internal taper of the implant (or only a small amount at the top of the abutment connection) is of importance to provide mechanical interlocking, abutment stability and bacterial sealing. The Morse locking tapered connection is shown to leave a gap, which is smaller than 1 micron, whereas the smallest bacterium measures approx. 1.5 microns.

In finite element studies Yao et al. (58) showed that the design optimization and is the 5.7-degree Morse-tapered connection not only reduces the possibility of abutment fracture but also increases the longevity of implant therapy (59) and overall patient satisfaction (60).

Today, there is only one clinical study comparing two implant systems with different implant-abutment connections and PS placed in the same patient and splinted together with a fixed prosthesis. The butt-joint and the Morse-tapered connection were compared in this prospective clinical study. The implants were placed with platforms at the bone level and restored with the final abutment at day of implant placement for immediate function. It was shown that $70 \%$ of the implants with the butt-joint connection presented more than $2 \mathrm{~mm}$ crestal bone loss in contrast to the implants with Morse tapered connections (11\%) (61).

The study also showed a significant difference in terms of bacteria presence at the implant-abutment interface (62). Specifically, the abutments were removed after 2 years of 
loading for bacteria analysis. In addition, chlorhexidine (CHX) was used to potentially decontaminate the implantabutment interface. There is evidence that butt-joint connections are not well sealed and presented periodontalpathogenic bacteria infiltration, which was no found in the conical connections (62). In addition, the efficacy of the CHX was minimal.

Thus, the type and design of the implant-abutment interface seem to have a fundamental difference in terms of bacteria penetration, preventing or allowing peri-implant inflammatory reactions and potentially establishing the resorption of the crestal bone. Based on this data, it can be concluded that when the crest of bone in the anterior mandible must be reduced to create sufficient interocclusal space for the prosthetic restoration using hybrid type of prostheses, or when implants even with PS are placed in the atrophic bone, there is an expectation of bone resorption independent on the implant-abutment connection and absence of micromovements (when implants are splinted).

Furthermore, the gentle bone preservation, especially in the anterior mandible, as well as the soft tissue thickness and presence of keratinized peri-implant mucosa, have shown to have an impact on crestal bone stability $(63,64)$.

\section{Summary}

In summary, there is a pantheon of components that must be considered and synchronized by clinicians based on knowledge and experience in understanding these sensitive and fundamental topics in implant dentistry. Specific implant design features provide important information for clinicians and manufacturers to create a better future for dental implants, especially if the host response changes over time. Biology and technological improvements must be considered when clinicians are placing implants especially in compromised sites and patients with systemic diseases. All these developments must be critically analyzed when new implant surfaces and implant-abutment connections are developed to improve strategies for better osseointegration and crestal bone stability.

\section{Acknowledgments}

The author would like with this paper to honor the $70^{\text {th }}$ birthday of Prof. Dr. Georg-Hubertus Nentwig and his legacy in Implant Dentistry.

Funding: None.

\section{Footnote}

Provenance and Peer Review: This article was commissioned by the Guest Editor (Ole T. Jensen) for the series "Current Advances in Treatment of Peri-Implantitis" published in Frontiers of Oral and Maxillofacial Medicine. The article has undergone external peer review.

Conflicts of Interest: The author has completed the ICMJE uniform disclosure form (available at https://fomm. amegroups.com/article/view/10.21037/fomm-21-73/ coif). The series "Current Advances in Treatment of PeriImplantitis" was commissioned by the editorial office without any funding or sponsorship. GER serves as an unpaid editorial board member of Frontiers of Oral and Maxillofacial Medicine from October 2021 to September 2023. The author has no other conflicts of interest to declare.

Etbical Statement: The author is accountable for all aspects of the work in ensuring that questions related to the accuracy or integrity of any part of the work are appropriately investigated and resolved.

Open Access Statement: This is an Open Access article distributed in accordance with the Creative Commons Attribution-NonCommercial-NoDerivs 4.0 International License (CC BY-NC-ND 4.0), which permits the noncommercial replication and distribution of the article with the strict proviso that no changes or edits are made and the original work is properly cited (including links to both the formal publication through the relevant DOI and the license). See: https://creativecommons.org/licenses/by-nc-nd/4.0/.

\section{References}

1. Hansson S. The implant neck: smooth or provided with retention elements. A biomechanical approach. Clin Oral Implants Res 1999;10:394-405.

2. Nentwig GH. Ankylos implant system: concept and clinical application. J Oral Implantol 2004;30:171-7.

3. Koutouzis T. Implant-abutment connection as contributing factor to peri-implant diseases. Periodontol 2000 2019;81:152-66.

4. Kuo RF, Yang CJ, Lin ZS. One Piece Dental Implant Development. In: Su FC, Wang SH, Yeh ML. (eds) 1st Global Conference on Biomedical Engineering \& 9th Asian-Pacific Conference on Medical and Biological 
Engineering. IFMBE Proceedings, vol 47. Springer, (2015). Cham.

5. Norton MR. Marginal bone levels at single tooth implants with a conical fixture design. The influence of surface macro- and microstructure. Clin Oral Implants Res 1998;9:91-9.

6. De Kok IJ, Chang SS, Moriarty JD, et al. A retrospective analysis of peri-implant tissue responses at immediate load/provisionalized microthreaded implants. Int J Oral Maxillofac Implants 2006;21:405-12.

7. Mertens C, Steveling HG. Early and immediate loading of titanium implants with fluoride-modified surfaces: results of 5-year prospective study. Clin Oral Implants Res 2011;22:1354-60.

8. Al-Thobity AM, Kutkut A, Almas K. Microthreaded Implants and Crestal Bone Loss: A Systematic Review. J Oral Implantol 2017;43:157-66.

9. Javed F, Romanos GE. Evidence-based Implant Dentistry and Systemic Conditions. Wiley Publ., Hoboken, 2018.

10. Binon PP. The effect of implant/abutment hexagonal misfit on screw joint stability. Int J Prosthodont 1996;9:149-60.

11. Binon PP, McHugh MJ. The effect of eliminating implant/ abutment rotational misfit on screw joint stability. Int $\mathrm{J}$ Prosthodont 1996;9:511-9.

12. Ericsson I, Persson LG, Berglundh T, et al. Different types of inflammatory reactions in peri-implant soft tissues. J Clin Periodontol 1995;22:255-61.

13. Hermann JS, Schoolfield JD, Schenk RK, et al. Influence of the size of the microgap on crestal bone changes around titanium implants. A histometric evaluation of unloaded non-submerged implants in the canine mandible. J Periodontol 2001;72:1372-83.

14. Hermann JS, Cochran DL, Nummikoski PV, et al. Crestal bone changes around titanium implants. A radiographic evaluation of unloaded nonsubmerged and submerged implants in the canine mandible. J Periodontol 1997;68:1117-30.

15. Weng D, Nagata MJ, Bell M, et al. Influence of microgap location and configuration on the periimplant bone morphology in submerged implants. An experimental study in dogs. Clin Oral Implants Res 2008;19:1141-7.

16. Weng D, Nagata MJ, Leite CM, et al. Influence of microgap location and configuration on radiographic bone loss in nonsubmerged implants: an experimental study in dogs. Int J Prosthodont 2011;24:445-52.

17. Sasada Y, Cochran DL. Implant-Abutment Connections: A Review of Biologic Consequences and Periimplantitis Implications. Int J Oral Maxillofac Implants
2017;32:1296-307.

18. Bicon history. Available online: https://www.bicon.com/b_ intro_history.html

19. Nentwig GH, Moser W. Available online: https://www. magicdentalstudio.pl/www/images/File/artykul/iD_0307_ Ankylos_fathers_Nentwig-Moser_en.pdf

20. Moser W, Nentwig G. Finite-Element-Studien zur Optimierung von Implantatgewindeformen. Z Zahnärztl Implantol 1989;V:29-32.

21. Nentwig GH, Mairgünther R. Reaktionen an der KnochenImplantatgrenze bei Brückenversongungen mit dem NMSystem. Z Zahnärztl Implantol 1992;VIII:251-253.

22. Zipprich H, Weigl P, Lange B, et al. Micromovements at the implant-abutment interface: measurement; causes; and consequences. Implantologie 2007;15:31-46.

23. Zipprich H, Weigl P, Ratka C, et al. The micromechanical behavior of implant-abutment connections under a dynamic load protocol. Clin Implant Dent Relat Res 2018;20:814-23.

24. Schmitt CM, Nogueira-Filho G, Tenenbaum HC, et al. Performance of conical abutment (Morse Taper) connection implants: a systematic review. J Biomed Mater Res A 2014;102:552-74.

25. Romanos GE, Aydin E, Gaertner K, et al. Longterm results after subcrestal or crestal placement of delayed loaded implants. Clin Implant Dent Relat Res 2015;17:133-41.

26. Froum SJ, Cho SC, Suzuki T, et al. Epicrestal and subcrestal placement of platform-switched implants: 18 month-result of a randomized, controlled, splitmouth, prospective clinical trial. Clin Oral Implants Res 2018;29:353-66.

27. Pellicer-Chover H, Peñarrocha-Diago M, Aloy-Prosper A, et al. Does Apico-Coronal Implant Position Influence Peri-Implant Marginal Bone Loss? A 36-Month FollowUp Randomized Clinical Trial. J Oral Maxillofac Surg 2019;77:515-27.

28. Abrahamsson I, Berglundh T, Lindhe J. The mucosal barrier following abutment dis/reconnection. An experimental study in dogs. J Clin Periodontol 1997;24:568-72.

29. Abrahamsson I, Berglundh T, Wennström J, et al. The peri-implant hard and soft tissues at different implant systems. A comparative study in the dog. Clin Oral Implants Res 1996;7:212-9.

30. Abrahamsson I, Berglundh T, Lindhe J. Soft tissue response to plaque formation at different implant systems. A comparative study in the dog. Clin Oral Implants Res 
1998;9:73-9.

31. Becker K, Mihatovic I, Golubovic V, et al. Impact of abutment material and dis-/re-connection on soft and hard tissue changes at implants with platform-switching. J Clin Periodontol 2012;39:774-80.

32. Canullo L, Pesce P, Tronchi M, et al. Marginal soft tissue stability around conical abutments inserted with the one abutment-one time protocol after 5 years of prosthetic loading. Clin Implant Dent Relat Res 2018;20:976-82.

33. Romanos GE. Surgical and prosthetic concepts for predictable immediate loading of oral implants. J Calif Dent Assoc 2004;32:991-1001.

34. Romanos GE. Advanced Immediate Loading. Quintessence Publ., Chicago, 2012.

35. Degidi M, Nardi D, Daprile G, et al. Nonremoval of immediate abutments in cases involving subcrestally placed postextractive tapered single implants: a randomized controlled clinical study. Clin Implant Dent Relat Res 2014;16:794-805.

36. Degidi M, Nardi D, Piattelli A. One abutment at one time: non-removal of an immediate abutment and its effect on bone healing around subcrestal tapered implants. Clin Oral Implants Res 2011;22:1303-7.

37. Romanos GE. Wound healing in immediately loaded implants. Periodontol 2000 2015;68:153-67.

38. Romanos GE, Toh CG, Siar CH, et al. Histologic and histomorphometric evaluation of peri-implant bone subjected to immediate loading: an experimental study with Macaca fascicularis. Int J Oral Maxillofac Implants 2002;17:44-51.

39. Romanos GE, Toh CG, Siar CH, et al. Bone-implant interface around titanium implants under different loading conditions: a histomorphometrical analysis in the Macaca fascicularis monkey. J Periodontol 2003;74:1483-90.

40. Romanos GE, Gaertner K, Nentwig GH. Longterm evaluation of immediately loaded implants in the edentulous mandible using fixed bridges and platform shifting. Clin Implant Dent Relat Res 2014;16:601-8.

41. Romanos GE, Nentwig GH. Immediate loading using cross-arch fixed restorations in heavy smokers: nine consecutive case reports for edentulous arches. Int J Oral Maxillofac Implants 2008;23:513-9.

42. Romanos GE, Gaertner K, Aydin E, et al. Long-term results after immediate loading of platform-switched implants in smokers versus nonsmokers with full-arch restorations. Int J Oral Maxillofac Implants 2013;28:841-5.

43. Romanos GE, Johansson CB. Immediate loading with complete implant-supported restorations in an edentulous heavy smoker: histologic and histomorphometric analyses. Int J Oral Maxillofac Implants 2005;20:282-90.

44. Romanos GE. Tissue preservation strategies for fostering long-term soft and hard tissue stability. Int J Periodontics Restorative Dent 2015;35:363-71.

45. Gardner DM. Platform switching as a means to achieving implant esthetics. N Y State Dent J 2005;71:34-7.

46. Lazzara RJ, Porter SS. Platform switching: a new concept in implant dentistry for controlling postrestorative crestal bone levels. Int J Periodontics Restorative Dent 2006;26:9-17.

47. Nevins M, Camelo M, Koo S, et al. Human histologic assessment of a platform-switched osseointegrated dental implant. Int J Periodontics Restorative Dent 2014;34 Suppl 3:s71-3.

48. Santiago JF, Lemos CAA, de Luna Gomes JM, et al. Quality Assessment of Systematic Reviews on PlatformSwitching vs Platform-Matched Implants: An Overview. J Oral Implantol 2020;46:153-62.

49. Romanos GE, Javed F. Platform switching minimises crestal bone loss around dental implants: truth or myth? J Oral Rehabil 2014;41:700-8.

50. Becker J, Ferrari D, Mihatovic I, et al. Stability of crestal bone level at platform-switched non-submerged titanium implants: a histomorphometrical study in dogs. J Clin Periodontol 2009;36:532-9.

51. Alrabeah GO, Knowles JC, Petridis H. The effect of platform switching on the levels of metal ion release from different implant-abutment couples. Int J Oral Sci 2016;8:117-25.

52. Alrabeah GO, Brett P, Knowles JC, et al. The effect of metal ions released from different dental implantabutment couples on osteoblast function and secretion of bone resorbing mediators. J Dent 2017;66:91-101.

53. Baffone GM, Botticelli D, Canullo L, et al. Effect of mismatching abutments on implants with wider platforms-an experimental study in dogs. Clin Oral Implants Res 2012;23:334-9.

54. Souza AB, Alshihri A, Kämmerer PW, et al. Histological and micro-CT analysis of peri-implant soft and hard tissue healing on implants with different healing abutments configurations. Clin Oral Implants Res 2018;29:1007-15.

55. Caram SJ, Huynh-Ba G, Schoolfield JD, et al. Biologic width around different implant-abutment interface configurations. A radiographic evaluation of the effect of horizontal offset and concave abutment profile in the canine mandible. Int J Oral Maxillofac Implants 2014;29:1114-22. 
56. Cochran DL, Bosshardt DD, Grize L, et al. Bone response to loaded implants with non-matching implantabutment diameters in the canine mandible. J Periodontol 2009;80:609-17.

57. Khorshidi H, Raoofi S, Moattari A, et al. In Vitro Evaluation of Bacterial Leakage at Implant-Abutment Connection: An 11-Degree Morse Taper Compared to a Butt Joint Connection. Int J Biomater 2016;2016:8527849.

58. Yao KT, Chen CS, Cheng CK, et al. Optimization of the Conical Angle Design in Conical Implant-Abutment Connections: A Pilot Study Based on the Finite Element Method. J Oral Implantol 2018;44:26-35.

59. Krebs M, Schmenger K, Neumann K, et al. Long-term evaluation of ANKYLOS® dental implants, part i: 20 year life table analysis of a longitudinal study of more than 12,500 implants. Clin Implant Dent Relat Res 2015;17 Suppl 1:e275-86.

60. Morris HF, Ochi S, Rodriguez A, et al. AICRG, Part IV: Patient satisfaction reported for Ankylos implant

doi: $10.21037 /$ fomm-21-73

Cite this article as: Romanos GE. The implant-abutment connection and its impact on prevention of peri-implant diseases and crestal bone stability-an academic and clinical evaluation of the literature. Front Oral Maxillofac Med 2023;5:7. prostheses. J Oral Implantol 2004;30:152-61.

61. Romanos GE, Malmstrom H, Feng C, et al. Immediately loaded platform-switched implants in the anterior mandible with fixed prostheses: a randomized, split-mouth, masked prospective trial. Clin Implant Dent Relat Res 2014;16:884-92.

62. Romanos GE, Biltucci MT, Kokaras A, et al. Bacterial Composition at the Implant-Abutment Connection under Loading in vivo. Clin Implant Dent Relat Res 2016;18:138-45.

63. Linkevicius T, Puisys A, Linkeviciene L, et al. Crestal Bone Stability around Implants with Horizontally Matching Connection after Soft Tissue Thickening: A Prospective Clinical Trial. Clin Implant Dent Relat Res 2015;17:497-508.

64. Romanos G, Grizas E, Nentwig GH. Association of Keratinized Mucosa and Periimplant Soft Tissue Stability Around Implants With Platform Switching. Implant Dent 2015;24:422-6. 